\title{
Top-down processing and the suffix effect in young and older adults
}

\author{
MAURA PILOTTI, TIM BEYER, and MARIYA YASUNAMI \\ Washington University, St. Louis, Missouri
}

\begin{abstract}
The suffix effect has generally been viewed as reflecting an automatic component involving the terminal item and a component susceptible to top-down influences involving the preterminal items (Balota \& Engle, 1981). Recent findings have raised questions about this widely accepted view of the suffix effect by showing that the terminal component is not insensitive to top-down influences (Bloom \& Watkins, 1999). In the present study, we attempted to uncover the source of these contradictory findings by assessing whether the terminal item's susceptibility to top-down influences might depend on subjects' first-hand experience of the extent to which recall is affected by the suffix. Furthermore, we examined whether age differences in the suffix effect could be attributed to age-related declines in inhibitory processes. Our findings supported both predictions.
\end{abstract}

In the standard suffix procedure, subjects hear lists of randomly organized digits or letters, followed by either a suffix (e.g., the word $g o$ ) or a silent interval of equivalent duration. Their task is to recall the digits or letters in the order in which they were presented and to ignore the suffix. When the recall of the suffix lists is compared with the recall of the control lists, there is a reliable increase in errors for the items in the proximity of the suffix, with the terminal item, which enjoys near-perfect performance in the control condition, displaying the largest increment in errors. This phenomenon is called the suffix effect.

One of the most widely known accounts of the suffix effect postulates that this phenomenon arises from two distinct memory mechanisms, each influencing primarily, but not exclusively, different portions of the serial position curve (Balota \& Engle, 1981; Greenberg \& Engle, 1983; Penney, 1985). According to this account (hereafter named the two-componentaccount), the effect of the suffix on the terminal item reflects, for the most part, an automatic form of processing typical of the functioning of echoic memory. That is, the suffix is thought of as masking the echoic memory trace of the terminal item, thereby impairing its recall (Cowan, 1984; Crowder, 1971, 1978; Crowder \& Morton, 1969; Greene \& Crowder, 1984). In contrast, the effect of the suffix on the preterminal items, which are the items most difficult to recall, is assumed to reflect, for the most part, subjects' failure to exclude the suffix from attention. As a result, the suffix is thought of as taking up re-

This work was supported by Grant F32 DC00342 from the National Institute on Deafness and Other Communication Disorders. We thank Ben Chi for his help in conducting the experiment. Correspondence concerning this article should be addressed to M. Pilotti, Department of Psychology, HunterCollege, 695 Park Avenue, New York, NY 10021(e-mail: mpilotti@hunter.cuny.edu).

-Accepted by previous editorial team sources that otherwise could be devoted to the preterminal items, further depressing their recall.

The burden of proof for the two-component account resides in the demonstration that factors that can modulate the allocation of attention affect the preterminal component of the suffix effect but have little or no influence on the terminal component. Among these factors, presentation rate and practice afford two of the most compelling tests for this account, because increased experience with the recall task and slowing the rate of presentation can promote attention to the recall lists, increasing the opportunities for top-down processing such as rehearsal and list organization. Accordingly, the two-component account predicts that practice and slowing the presentation rate should reduce the preterminal component of the suffix effect but should have less influence (if any) on the terminal component if this effect arises from the suffix's masking the echoic trace of the last item.

The few studies that have examined the influence of rate and practice on the suffix effect in young adults have reported contradictory results. For instance, Bloom and Watkins (1999) found that slowing the presentation rate and practice reduced the terminal, but not the preterminal, component of the suffix effect, whereas Balota and Engle (1981) reported that these factors influenced the preterminal component only. The most striking methodological difference between these studies involves the administration of suffix and control lists. Bloom and Watkins used a within-subjects design with random presentation, whereas Balota and Engle adopted either a between-subjects design (Session 1) or a blocked presentation (Session 2). If the reason for focusing attention on specific list items is the difficulty with which they are recalled, as was postulated by Balota and Engle, can these contradictory findings reflect the allocation of attention to different list items, shaped by subjects' experience with the suffix? Of course, for subjects exposed to both suffix and control lists, as in the Bloom and 
Watkins study, the terminal item, which displays nearperfect recall in the control lists, displays the largest decrement in recall in the suffix lists. Consequently, one would expect subjects to direct attention to the terminal item as a way of improving its recall, making the effect of the suffix on this item susceptible to top-down processing (as was reported by Bloom \& Watkins). In contrast, for subjects exposed to only one type of list, as in Session 1 of the Balota and Engle experiment, the difficulty of recalling the preterminal items (either with or without the suffix) is likely to be the most salient aspect of their performance. Consequently, one would expect subjects to focus attention on these items to ameliorate their recall (as was reported by Balota \& Engle in Session 1). Prior practice with only one type of list may also be expected to preserve this strategy even though subjects recall both types of lists (as was reported by Balota \& Engle in Session 2).

In light of these assumptions, the goal of the present study was to test the hypothesis that direct knowledge of the effect of the suffix on recall can modulate the allocation of attention in the stimulus suffix paradigm. To this end, we examined the effect of the suffix on subjects' recall as a function of practice, presentation rate, and administration of suffix and control lists. With respect to the latter factor, the subjects received either control or suffix lists (betweensubjects condition) or both lists presented in separate blocks (blocked condition). The subjects were warned, via instructions and training trials, as to the type of lists they were required to recall prior to each block or during the entire experimental session, so that the occurrence of the suffix was predictable in both experimental conditions. This design permitted us to assess whether the effects of top-down processing, which Bloom and Watkins (1999) found to be limited to the terminal item with random presentation of suffix and control lists, could be attributed to subjects' attempts to predict the occurrence of the suffix. Specifically, we examined whether subjects exposed to both suffix and control lists would extend attention to the preterminal items when the occurrence of the suffix was entirely predictable.

In the present study, we examined the suffix effect not only in young adults, but also in older adults, as an additional test of the two-component account. Surprisingly, the handful of studies that have investigated the suffix effect in different age groups not only have neglected to provide a direct test for this account, but also have yielded contradictory findings. For instance, Manning and GreenhutWertz (1990) asked young and older adults to recall 16 six-letter lists, half with the suffix and half without it, all auditorily presented at a rate of one letter per second. With suffix and control lists in separate blocks, Manning and Greenhut-Wertz found no age differences in the terminal component of the suffix effect, but a larger preterminal component in the aged. In contrast, Wiseman (1998), who used a similar experimental design, found age differences in both the terminal and the preterminal components. In light of these contradictory findings, in the present study, we relied on evidence from the literature on aging to formulate three predictions with respect to older adults' recall in the stimulus suffix paradigm. First, evidence of age-related declines in inhibitory processes (see Carlson, Hasher, Connelly, \& Zacks, 1995; Connelly, Hasher, \& Zacks, 1991; Hasher \& Zacks, 1988; Zacks \& Hasher, 1994) led to the prediction that excluding the suffix from attention would be particularly arduous for older adults. Consequently, older adults were expected to exhibit a larger suffix effect on the items whose processing depends on attentional resources. The two-component account predicts that the resource-dependent nature of the preterminal suffix effect would make this effect susceptible to the influence of agerelated declines in inhibitory processes, whereas the automatic nature of the terminal suffix effect would shield this effect from such declines. In contrast, the hypothesis that direct knowledge of the effect of the suffix on recall might modulate the allocation of attention to specific list items led to the prediction that age differences in the preterminal and terminal components of the suffix effect would depend on the administration of list type. Second, evidence of age-related declines in temporal memory (Fabiani \& Friedman, 1997; Lowe \& Rabbitt, 1997; Maylor, Vousden, \& Brown, 1999; Parkin, 1997) led to the prediction that older adults would yield an overall lower recall rate, with age-related declines in inhibitory functioning further depressing recall in the suffix lists. Lastly, evidence that older adults' recall improves with practice (Taub, 1973; Taub \& Long, 1972) and slowing the rate of presentation (Wingfield, Poon, Lombardi, \& Lowe, 1985) suggested that these factors might attenuate the effect of the suffix on the items that are sensitive to shifts in attentional resources. As was discussed earlier, the two-component account and the hypothesis proposed here made quite different predictions as to which items might be sensitive to such shifts.

\section{METHOD}

\section{Subjects}

The subjects were 180 young adults and 160 older adults. The young adults were Washington University undergraduate students, who participated in the experiment for course credit. Their mean age was 19.40 years (16-31). The older adults were community members from the Aging and Development Subject Pool, who were paid for their participation. Their mean age was 75.61 years $(60-86)$. All the subjects reported themselves as being in a healthy condition for their age, and none wore a hearing aid. They were given the vocabulary subsection of the Shipley test (Shipley, 1940) to ascertain their cognitive status. The mean vocabulary score of young adults was $33.60(S D=2.61)$, and the mean vocabulary score of older adults was $35.48(S D=2.60)$. Sixty-eight young adults and 64 older adults participated in the between-subjects condition (fast-rate, 16 young and 16 older adults per list type; slow-rate, 18 young and 16 older adults per list type). Fifty-six young adults and 48 older adults participated in the blocked condition ( 28 young and 24 older adults per presentation rate). The same number of subjects participated in a blocked condition involving eight digits (described below). Three older adults who either repeatedly recalled a digit that was not part of the stimulus material (seven) or displayed difficulties in understanding the instructions were excluded from the experiment.

\section{Stimuli, Procedure, and Design}

The stimuli of this experiment consisted of the digits 1-9 (excluding the bisyllabic digit 7), and the word go, all spoken by a male talker, digitized at a $20-\mathrm{kHz}$ sampling rate, and equated in amplitude 
Table 1

The Influence (in Percentages) of Age, Practice, and Rate on the Terminal and Preterminal Suffix Effects, in Each Experimental Condition

\begin{tabular}{|c|c|c|c|}
\hline Factor & Between Subjects & Blocked & Blocked (8 digits) \\
\hline \multicolumn{4}{|l|}{ Terminal Item } \\
\hline Age (young vs. old) & 16 vs. 19 & 10 vs. $27 *$ & 17 vs. $27 *$ \\
\hline Practice (before vs. after) & 18 vs. 16 & 22 vs. $15 * *$ & 28 vs. $16 *$ \\
\hline Rate (fast vs. slow) & 18 vs. 17 & 20 vs. 16 & 27 vs. $17 *$ \\
\hline \multicolumn{4}{|l|}{ Preterminal Items } \\
\hline Age (young vs. old) & 4 vs. $15 *$ & 6 vs. $12 *$ & 6 vs. $13 *$ \\
\hline Practice (before vs. after) & 12 vs. $7 *$ & 13 vs. $5^{*}$ & 12 vs. $6 *$ \\
\hline Rate (fast vs. slow) & 7 vs. 12 & 10 vs. 8 & 10 vs. 9 \\
\hline
\end{tabular}

*Effect reliable at $p<.05 . \quad * *$ Effect reliable only in young adults.

and length $(400 \mathrm{msec})$. Prior to the experiment, the loudness of the stimulus material was adjusted separately for each subject via a brief identification test to ensure audibility.

In the experiment, the subjects received 96 experimental lists, constructed by sampling without replacement either seven or eight digits, within the constraints that no consecutive digits could be neighbors. There were two experimental conditions, each unique with respect to the way suffix and control lists were administered. In the between-subjects condition, the subjects heard two blocks of 48 seven-digit lists, all of one type (either suffix or control). In the blocked condition, the subjects received two blocks of seven-digit lists, one with 48 suffix lists, and the other with 48 control lists, with the order in which blocks were presented counterbalanced across subjects. The blocked condition was replicated with eight-digit lists, to assess whether increasing the demands of the recall task would preserve the results observed with seven-digit lists. In all the conditions, practice effects were measured as recall rate changes from the first block of 48 lists to the second block of 48 lists (before practice vs. after practice). Furthermore, in all the conditions, the rate at which digits were presented was manipulated between subjects to ensure the development of listening strategies specific to the prevailing presentation rate. Thus, half of the subjects heard digits at a slow rate (1 digit/ sec) and half at the fast rate ( 2 digits/sec).

An experimental trial consisted of a sequence of digits, followed by either the suffix $g o$ in rhythm with the digits or a silent interval of equivalent duration (400 msec). A 400-msec tone serving as a cue for the subjects to start their recall was placed $4 \mathrm{sec}$ after the last digit for both the suffix and the control sequences (see Balota \& Engle, 1981). The tone was followed by a 15 -sec silent interval, during which the subjects were instructed to report the digits in strict serial order, without making corrections or backtracking on a response sheet containing either seven or eight rows. In the blocked condition and in the between-subjects condition involving suffix lists, the subjects were informed that the word go would occur at the end of some (or all) sequences of digits. They were instructed to ignore the word and not recall it along with the digits. All the subjects initiated each trial by pressing the Enter key of the computer keyboard. The subjects were given 10 training trials to familiarize themselves with the assigned presentation rate and type(s) of list. Depending on the experimental condition, the training trials contained either suffix and control lists or only one type of list. The experiment involved the following factors: experimental condition (between subjects vs. blocked), age (young vs. old), serial position (preterminal vs. terminal), list type (suffix vs. control), practice (before practice vs. after practice), and presentation rate (fast vs. slow).

\section{RESULTS}

A strict scoring procedure was utilized for the analyses, so that a 1 was given for a correct digit recalled in the cor- rect serial position and a 0 was given in any other case. For the purpose of our study, the statistical analyses focused on the last five serial positions (see Bloom \& Watkins, 1999). The four serial positions prior to the last are referred to as preterminal positions. Therefore, any reliable decrement in the recall of the preterminal items (averaged across these items) owing to the presence of the suffix represents the preterminal suffix effect. Position 7 (or 8 in eightdigit lists) is referred to as the terminal position, and any decrement in the recall of the last item owing to the presence of the suffix represents the terminal suffix effect. Figures 1-3 display the mean percentage of correct recall in each experimental condition as a function of age, serial position (1-7 or 1-8), list type, practice, and presentation rate, whereas Table 1 displays changes in the preterminal and terminal suffix effects owing to age, practice, and rate.

The findings of this experiment can be summarized in three points (see Table 1). First, when the subjects recalled only one type of list (between-subjects condition), age differences emerged in the preterminal component of the suffix effect. However, when the subjects recalled both suffix and control lists (blocked condition), age differences involved the terminal and the preterminal components of the suffix effect. Second, practice reduced the terminal and preterminal suffix effects in the blocked condition, whereas practice reduced only the preterminal suffix effect in the between-subjects condition. Third, the effects of slowing the rate of presentation were weak overall across all the experimental conditionsand age groups. These observations were supported by a 2 (young vs. old) $\times 2$ (suffix vs. control list) $\times 2$ (slow vs. fast) $\times 2$ (before vs. after practice) analysis of variance (ANOVA) on the percentage of correct responses at the terminal and preterminal positions in each experimental condition. Note that the results reported here are significant at the .05 level, unless otherwise indicated.

\section{Between-Subjects Condition (Seven-Digit Lists)}

Terminal item. In both age groups, the suffix depressed the recall of the terminal item $\left[F(1,124)=54.63, M S_{\mathrm{e}}=\right.$ 355.79], but young adults were overall better at recalling this item than were older adults $\left[F(1,124)=24.27, M S_{\mathrm{e}}=\right.$ $355.79]$. No other effects reached significance $\left(F_{\mathrm{S}}<2.3\right)$, suggesting that age, practice, and rate did not reliably affect the terminal component of the suffix effect. 

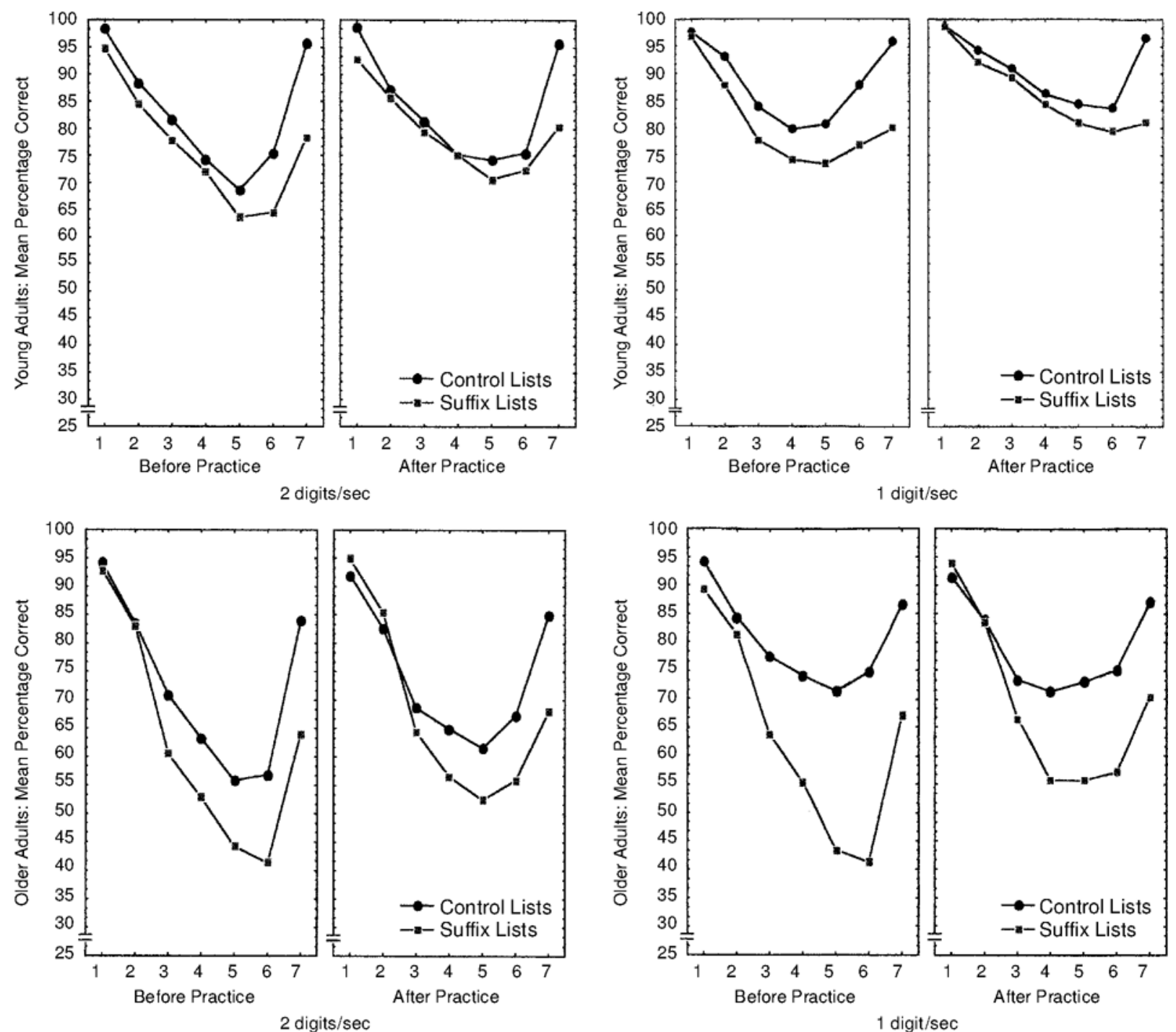

Figures 1. Mean percentages of correct recall in young and older adults as a function of serial position, list type, practice, and presentation rate in the between-subjects condition.

Preterminal items. Although the suffix affected the recall of the preterminal items in both age groups $[F(1,124)=$ $\left.19.73, M S_{\mathrm{e}}=302.72\right]$, recall was higher overall in young adults $\left[F(1,124)=59.40, M S_{\mathrm{e}}=302.72\right]$. In both age groups, recall increased with slowing the rate of presentation $\left[F(1,124)=10.608, M S_{\mathrm{e}}=302.72\right]$ and improved as a function of practice $\left[F(1,124)=15.93, M S_{\mathrm{e}}=83.10\right]$. The preterminal suffix effect increased with age $F(1,124)=$ $5.44, M S_{\mathrm{e}}=302.72$, and decreased with practice $[F(1,124)=$ $\left.5.49, M S_{\mathrm{e}}=83.10\right]$. No other effects were reliable, $\left(F_{\mathrm{S}}<\right.$ 1.4). ${ }^{1}$

\section{Blocked Condition (Seven-Digit Lists)}

Terminal item. The suffix affected the recall of the terminal item in both age groups $\left[F(1,96)=89.44, M S_{\mathrm{e}}=\right.$
191.22], but older adults recalled this item less well than did young adults $\left[F(1,96)=39.78, M S_{\mathrm{e}}=361.06\right]$. Older adults also yielded a larger terminal suffix effect than young adults $\left[F(1,96)=19.33, M S_{\mathrm{e}}=191.22\right]$. Although, in both age groups, overall performance was higher after practice $\left[F(1,96)=5.89, M S_{\mathrm{e}}=361.06\right]$, the influence of practice on the terminal suffix effect was only marginally significant $\left[F(1,96)=3.20, M S_{\mathrm{e}}=191.22, p=.08\right.$; other $\left.F_{\mathrm{S}}<1.3\right]$. Tests of simple effects indicated that practice reliably reduced the terminal suffix effect in young adults $\left[F(1,54)=5.79, M S_{\mathrm{e}}=58.61 ; 13 \%\right.$ vs. $\left.6 \%\right]$, but not in older adults $(F=1 ; 30 \%$ vs. $23 \%$ ), even though there was a similar reduction in the overall size of this effect.

Preterminal items. In both age groups, the suffix affected the recall of the preterminal items $[F(1,96)=48.37$, 

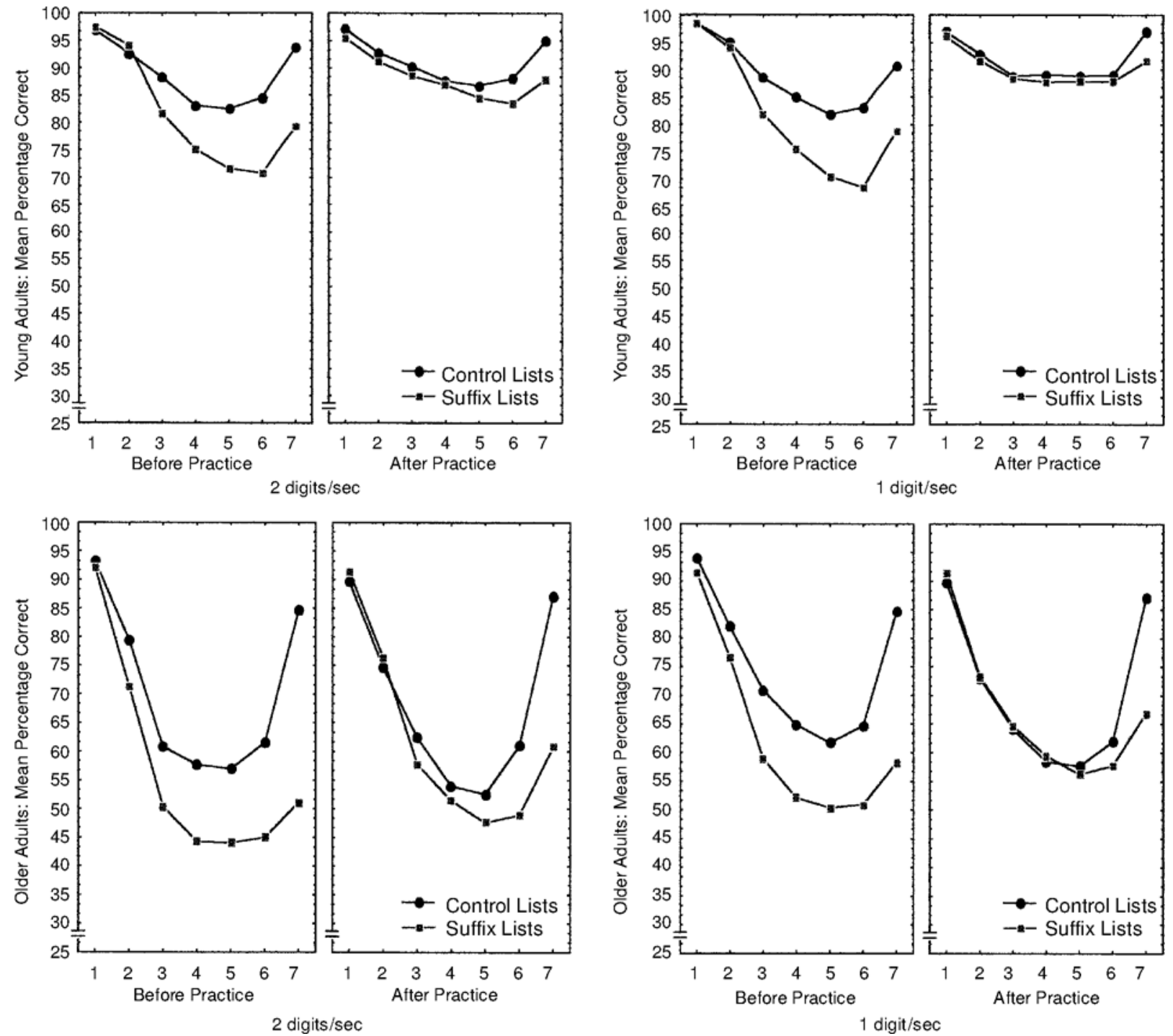

Figure 2. Mean percentages of correct recall in young and other adults as a function of serial position, list type, practice, and presentation rate in the blocked condition.

$\left.M S_{\mathrm{e}}=84.67\right]$, and practice had a marginally beneficial effect on overall performance $\left[F(1,96)=3.18, M S_{\mathrm{e}}=436.08, p=\right.$ $.08]$. Young adults recalled more preterminal items than older adults $\left[F(1,96)=67.14, M S_{\mathrm{e}}=436.08\right]$ and had a smaller preterminal suffix effect $\left[F(1,96)=5.46, M S_{\mathrm{e}}=\right.$ 84.67]. Practice reduced the preterminal suffix effect in both age groups $\left[F(1,96)=11.46, M S_{\mathrm{e}}=84.67\right.$; other $F \mathrm{~s}<$ 1.1 ; see note 1$]$.

\section{Blocked Condition (Eight-Digit Lists)}

Terminal item. Although the suffix affected the recall of the terminal item in both age groups $[F(1,96)=122.34$, $\left.M S_{\mathrm{e}}=209.82\right]$, young adults were better overall at recalling this item than were older adults $[F(1,96)=22.94$, $\left.M S_{\mathrm{e}}=352.05\right]$. In both age groups, overall performance was higher after practice $\left[F(1,96)=19.39, M S_{\mathrm{e}}=352.05\right]$ and at the slow rate $\left[F(1,96)=6.43, M S_{\mathrm{e}}=352.05\right]$. Older adults yielded a larger terminal suffix effect than did young adults $\left[F(1,96)=6.02, M S_{\mathrm{e}}=209.82\right]$, and practice reduced the terminal suffix effect in both groups $[F(1,96)=$ 9.36, $\left.M S_{\mathrm{e}}=209.82\right]$. Interestingly, although slowing the rate of presentation also reduced the terminal suffix effect in both age groups $\left[F(1,96)=6.29, M S_{\mathrm{e}}=209.82\right]$, a test of simple effects illustrated that the influence of rate was reliable only after practice $\left[F(1,48)=4.19, M S_{\mathrm{e}}=168.89\right.$; other $F \mathrm{~s}<1.3$ ].

Preterminal items. The preterminal items displayed a main effect for all the factors involved: list type, age, practice, and rate. These effects indicated that although the suffix affected the recall of the preterminal items in both age 

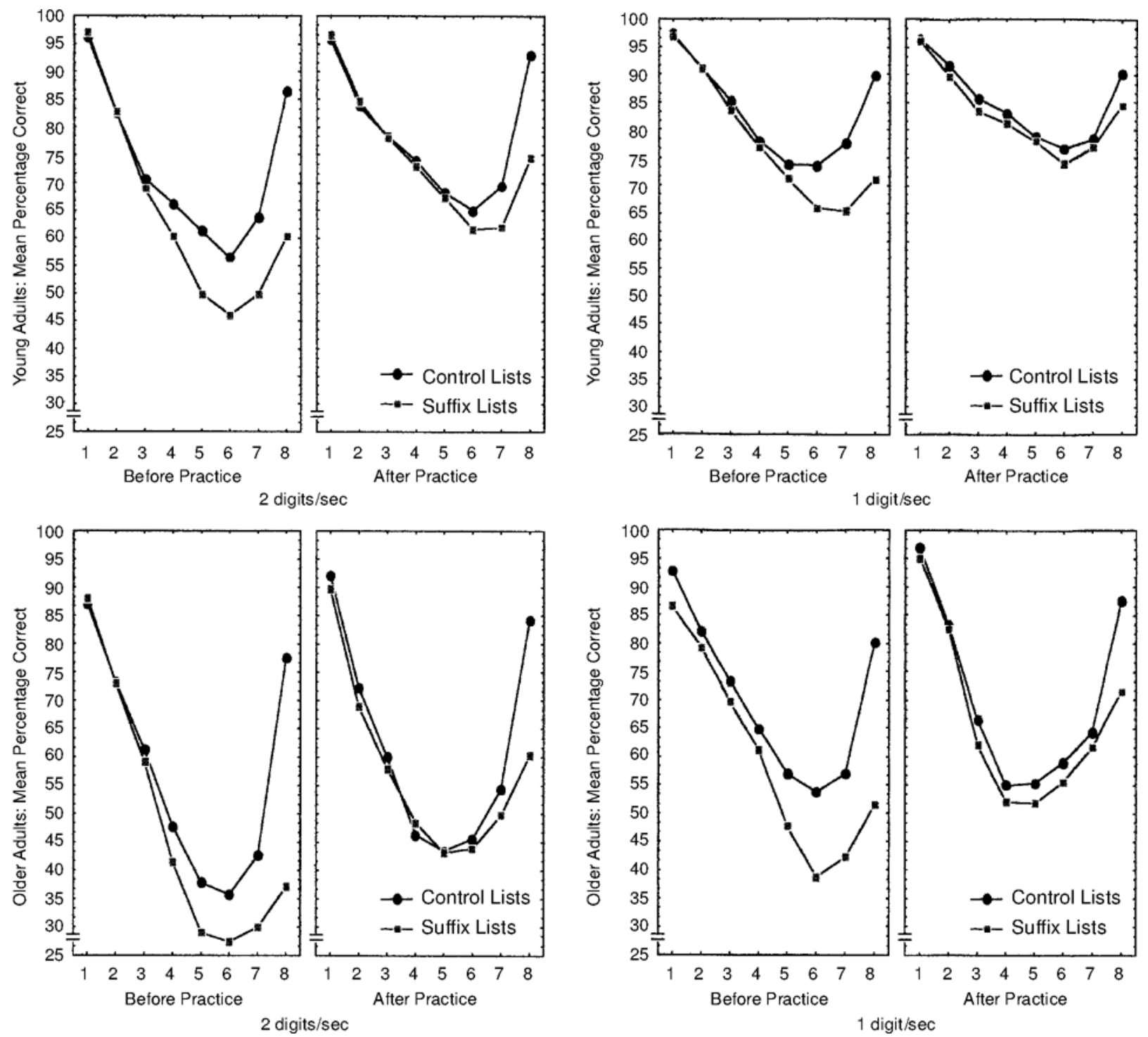

Figure 3. Mean percentages of correct recall in young and other adults as a function of serial position, list type, practice, and presentation rate in the blocked condition with eight-digit lists.

groups $\left[F(1,96)=60.51, M S_{\mathrm{e}}=65.80\right]$, overall performance was higher in young adults $\left[F(1,96)=26.70, M S_{\mathrm{e}}=\right.$ 593.66]. In both age groups, performance increased with slowing the rate of presentation $\left[F(1,96)=5.47, M S_{\mathrm{e}}=\right.$ 593.66] and improved as a function of practice $[F(1,96)=$ $\left.14.14, M S_{\mathrm{e}}=593.66\right]$. Older adults yielded a larger preterminal suffix effect $\left[F(1,96)=9.52, M S_{\mathrm{e}}=65.80\right]$, and practice reduced the preterminal suffix effect in both age groups $\left[F(1,96)=7.80, M S_{\mathrm{e}}=65.80\right.$; other $\left.F \mathrm{~s}<1\right]$.

\section{GENERAL DISCUSSION}

In the present experiment, we found that, when the subjects recalled both the suffix and the control lists in sepa- rate blocks, top-down processing (via practice) influenced both the terminal and the preterminal components of the suffix effect. In contrast, when the subjects recalled one type of list, top-down processing influenced only the preterminal component. These results are consistent with two basic assumptions regarding subjects' perceptions and corresponding reactions to the effects of the suffix on recall. First, attention to specific list items is driven by the difficulty with which they are recalled (Balota \& Engle, 1981). Second, subjects' assessment of which items are difficult to recall is shaped by their experiences with the effects of the suffix on recall, which depend on the administration of list type. We have argued earlier that when subjects recall both suffix and control lists, the terminal item, which en- 
joys near-perfect performance in the control lists, becomes relatively more difficult to recall in the suffix lists. In contrast, when subjects recall either type of list, they do not have the opportunity to experience how the recall of the terminal item changes as a function of the presence of the suffix. Thus, for these subjects, the preterminal items are likely to be perceived as the most difficult to recall, relative to all the other items (including the terminal item). Our findings indicate that subjects' direct experience with the effect of the suffix on recall afforded by the withinsubjects design directs attention to the terminal item and thus determines the terminal component's susceptibility to top-down influences. Furthermore, the findings of our experiment and those of Bloom and Watkins (1999) suggest that, when list type is administered within subjects, the predictability of the suffix plays a role in directing subjects' attention to the preterminal items. Specifically, blocked presentation of suffix and control lists permits subjects to direct attention to the preterminal items, whereas random presentation leads subjects to restrict attention to the terminal item (as was shown by Bloom \& Watkins, 1999), perhaps as a result of their attempts to predict the occurrence of the suffix. However, even with a predictable suffix, the influence of practice on the preterminal suffix effect may require a large number of trials before it can actually be detected. In fact, Watkins and Sechler (1989, Experiment 1), who also adopted a blocked design for list type but used a smaller number of lists, found that practice only produced a trend in the direction of a decrement in the preterminal component (see their Figure 1, Block 1 vs. Block 3, p. 683).

Interestingly, the subjects of our study were not equally sensitive to the two factors that were assumed to modulate top-down processing in the stimulus suffix paradigm: practice and rate. As was discussed earlier, the influence of practice was robust. In contrast, slowing the presentation rate had an overall beneficial effect on the recall of the preterminal items of the suffix and control lists in the between-subjects condition and reduced the terminal suffix effect in the blocked condition involving eight-digit lists, but only after practice. The overall beneficial effect of slowing the presentation rate on the preterminal items in the between-subjects condition indicates that a slow rate may help subjects, who are recalling either suffix or control lists, to encode the list items that are the most in need of processing in both lists. It also suggests that, for these subjects, slowing the rate of presentation is unlikely to contribute to the development of strategies directed at excluding the suffix from attention. However, how can we explain the finding of the blocked condition (eight-digit lists) in which a slower rate reduced the effect of the suffix, but only on the terminal item and after practice? There are two points to consider here. First, in this condition, slowing the presentation rate had a beneficial effect on the recall of the preterminal and terminal items of both suffix and control lists, as predicted by our hypothesis. Thus, as was discussed earlier, slowing the rate of presentation may help subjects, whose task is to recall both suffix and control lists, to encode the list items that are deemed to be in need of additional processing. Second, at the fast rate, the terminal suffix effect observed with eight-digit lists was relatively larger than the terminal suffix effect observed with seven-digit lists. A larger terminal suffix effect has more latitude to be influenced by encoding strategies that subjects may have developed during the first block of trials. Thus, if a slow rate of presentation facilitates the application of such strategies, it is not surprising that its influence was detected on the terminal item of eight-digit lists.

With respect to aging, the present study yielded an interesting pattern of results. Given the age-related declines in inhibitory processes documented in the literature, we hypothesized that older adults would be more affected by the presence of the suffix. Specifically, we expected agerelated declines in inhibitory processes to magnify subjects' difficulties in excluding the suffix from attention, allowing the suffix to take away a larger portion of the processing resources that could be allocated to specific list items. In the present study, older adults not only performed less well than young adults across all the experimental conditions and list types, but also displayed an increased effect of the suffix on those sections of the recall lists that produced reliable practice effects. Two points can be made with respect to these findings: First, because age differences in the suffix effect mirrored the influence of practice, such differences appear to reflect older adults' failure to focus attention on specific portions of the recall lists while attempting to exclude the suffix from attention. However, across all the experimental conditions, even young adults were not able to eliminate the disrupting effect of the suffix on recall, suggesting that age-related declines in inhibitory processes simply magnify subjects' pre-existing difficulties in ignoring a task-irrelevant stimulus. Second, because there were age differences in overall recall, older adults' performance in the stimulus suffix paradigm appears to reflect age-related declines not only in inhibitory processes, but also in memory for temporal order (Fabiani \& Friedman, 1997; Maylor et al., 1999). Declines in temporal memory have been generally attributed to older adults' failure to use contextual information efficiently (see Parkin, 1997), arising from selective neural losses in the prefrontal cortex (Lowe \& Rabbitt, 1997). These difficulties can be assumed to produce more displacement errors (recalling a digit in the incorrect position), yielding the lower recall rate observed in the present experiment.

The age differences uncovered in the present study are consistent with those reported by Wiseman (1998), who administered suffix and control lists in separate blocks and found age differences in both the terminal and the preterminal components of the suffix effect. They conflict, however, with those reported by Manning and GreenhutWertz (1990), who adopted the same design but found age differences only in the preterminal component. Unfortunately, both experiments involved a limited number of ex- 
perimental trials per list type and did not include training trials. Thus, their findings may reflect differences in how separate groups of subjects initially adjust to the stimulus suffix procedure. Of course, this argument does not apply to the study by Parkinson and Perey (1980), who compared the performance of 10 older adults in the stimulus suffix paradigm with that of a large group of young adults with different digit spans. In this experiment, subjects recalled 120 lists (60 per list type) organized in blocks of 30 . With the young adults' data collapsed across digit span, age differences emerged in both the terminal and the preterminal suffix effects. In the present study, we also found such differences in the blocked condition, suggesting that the subjects in the Parkinson and Perey study focused attention on both the preterminal and the terminal items of the recall lists. However, Parkinson and Perey did not alert subjects to the effect of the suffix on recall prior to the experimental session and did not examine performance as a function of practice. Therefore, it is possible that, in this experiment, the age differences observed on the terminal component emerged only after the first two blocks of trials - that is, after the subjects had the opportunity to be exposed to both suffix and control lists.

\section{REFERENCES}

Balota, D. A., \& ENGLe, R. W. (1981). Structural and strategic factors in the stimulus suffix effect. Journal of Verbal Learning \& Verbal Behavior, 20, 346-357.

Bloom, L. C., \& Wat Kins, M. J. (1999). Two-component theory of the suffix effect: Contrary findings. Journal of Experimental Psychology: Learning, Memory, \& Cognition, 25, 1452-1475.

Carlson, M. C., Hasher, L., Connelly, S. L., \& Zacks, R. T. (1995). Aging, distraction, and the benefits of predictable location. Psychology \& Aging, 10, 427-436.

Connelly, S. L., Hasher, L., \& Zacks, R. T. (1991). Age and reading: The impact of distraction. Psychology \& Aging, 6, 533-541.

Cowan, N. (1984). On long and short auditory stores. Psychological Bulletin, 96, 341-370.

Crowder, R. G. (1971). The sound of vowels and consonants in immediate memory. Journal of Verbal Learning \& Verbal Behavior, 10, 587-596.

Crowder, R. G. (1978). Mechanisms of auditory backward masking in the stimulus suffix effect. Psychological Review, 85, 502-524.

Crowder, R. G., \& Morton, J. (1969). Precategorical acoustic storage (PAS). Perception \& Psychophysics, 5, 365-373.

Fabiani, M., \& Friedman, D. (1997). Dissociations for temporal order and recognition memory in aging. Neuropsychologia, 35, 129-141.

Greenberg, S. N., \& Engle, R. W. (1983). Voice changes in the stimulus suffix effect: Are the effects structural or strategic? Memory \& Cognition, 11, 551-556.

Greene, R. L. \& Crowder, R. G. (1984). Modality and suffix effects in the absence of auditory stimulation. Journal of Verbal Learning \& Verbal Behavior, 23, 371-382.

HASHER, L., \& ZACKS, R. T. (1988). Working memory, comprehension, and aging: A review and a new view. In G. H. Bower (Ed.), The psychology of learning and motivation: Advances in research and theory (Vol. 22, pp. 193-225). New York: Academic Press.

Lowe, C., \& RABBitT, P. (1997). Cognitive models of ageing and frontal lobe deficits. In P. Rabbitt (Ed.), Methodology of frontal and executive function (pp. 39-59). Hove, U.K.: Psychology Press.

Manning K. S., \& Greenhut-Wertz, J. (1990). Visual and auditory modality and suffix effects in young and elderly adults. Experimental Aging Research, 16, 3-9.

Maylor, E. A., Vousden, J. I., \& Brown, G. D. A. (1999). Adult age differences in short-term memory for serial order: Data and model. Psychology \& Aging, 14, 572-594.

PARKIN, A. J. (1997). Normal age-related memory loss and its relation to frontal lobe dysfunction. In P. Rabbitt (Ed.), Methodology of frontal and executive function (pp. 177-190). Hove, U.K.: Psychology Press.

Parkinson, S. R, \& Perey, A. (1980). Aging, digit span, and the stimulus suffix effect. Journal of Gerontology, 35, 736-742.

Penney, C. G. (1985). Elimination of the suffix effect on preterminal items with unpredictable list length: Evidence for a dual model of suffix effects. Journal of Experimental Psychology: Learning, Memory, \& Cognition, 11, 229-247.

SHIPLEY, W. C. (1940). A self-administering scale for measuring intellectual impairment and deterioration. Journal of Psychology, 9, 371-377.

TAUB, H. A. (1973). Memory span, practice, and aging. Journal of Gerontology, 28, 335-338.

TAUB, H. A., \& Long, M. K. (1972). The effects of practice on shortterm memory of young and old subjects. Journal of Gerontology, 27, 494-499.

Wat Kins, M. J., \& Sechler, E. S. (1989). Adapting to an irrelevant item in an immediate recall task. Memory \& Cognition, 17, 682-692.

Wingfield, A., Poon, L. W., Lombardi, L., \& Lowe, D. (1985). Speed of processing in normal aging: Effects of speech rate, linguistic structure, and processing time. Journal of Gerontology, 40, 579-585.

Wiseman, T. A. (1998). Frequency, intrusions, and suffix effects in immediate recall and delayed recall as a function of aging and Alzheimer's disease. Unpublished doctoral dissertation, Graduate Center of the City University of New York.

ZACKS, R. T., \& HASHER, L. (1994). Directed ignoring: Inhibitory regulation of working memory. In D. Dagenbach \& T. H. Carr (Eds.), Inhibitory processes in attention, memory, and language (pp. 241-264). San Diego: Academic Press.

\section{NOTE}

1. Young adults' recall scores were relatively high, raising the question of whether high- and low-performing young adults might have been differentially affected by the presence of the suffix. To address this issue, we organized young adults in two groups, high- and low-scoring subjects, and assessed the effects of list type, practice, rate, and subgroup on recall.

Between-subjects condition. The terminal suffix effect was larger for the low-scoring subjects $\left[F(1,60)=14.76, M S_{\mathrm{e}}=185.92\right]$, but such a difference did not interact with either practice or rate. In contrast, the preterminal suffix effect illustrated a complex pattern of interactions involving practice, rate, and list type. Specifically, before practice, slowing the presentation rate did not affect the preterminal suffix effect in either lowor high-scoring subjects $(F \mathrm{~s}<1)$. After practice, slowing the presentation rate increased the preterminal suffix effect in low-scoring subjects [i.e., it improved recall in the control lists more than in the suffix lists; $\left.F(1,30)=5.70, M S_{\mathrm{e}}=86.39\right]$ and decreased it in high-scoring subjects $\left[F(1,30)=13.37, M S_{\mathrm{e}}=31.04\right]$.

Blocked condition (seven digits). The terminal and preterminal suffix effects were larger for low-scoring subjects $\left[F(1,48)=18.04, M S_{\mathrm{e}}=46.04\right.$, and $F(1,48)=7.56, M S_{\mathrm{e}}=25.69$, respectively]. However, these differences did not interact with either rate or practice $(F \mathrm{~s}<1)$.

(Manuscript received May 12, 2000; revision accepted for publication October 11, 2001.) 